recruited as three volunteers from the first set of experiments were not happy to swallow an intraduodenal tube.

Fluctuations in basal SMABF between different test days do, in our review, reflect acceptable physiological variations. As all determinations were performed by the same investigator (CS), the fluctuations cannot be attributed to an interobserver variabiality.

(3) We have measured postprandial secretin, cholecystokinin, and gastrin concentrations for many years. ${ }^{8-10}$ We did not measure these in the present study, because we felt that the plasma concentrations did not add any new pertinent information. We acknowledge the references stated with regard to glucagon values found postprandially. Even if the glucagon dose employed induced an increase at the upper limit of physiological glucagon concentrations, we still believe that our conclusions are valid and this is underlined by the lack of change in SMABF observed in our study with this dose of glucagon.

We cannot comment on the unpublished data discussed in the letter, as they are not available yet.

In summary, we have presented data on specific mechanisms regulating postprandial mesenteric artery blood flow using the echoDoppler flowmetry. Quantitative studies of postprandial hyperaemia are important for the understanding of normal physiological processes. We therefore hope that future research by various groups (as the group of Dr Wells) will be able to shed more light into the physiology and pathophysiology of intestina blood flow regulation.

CORNEL SIEBER Hepatic Hemodynamic Laboratory $111 / \%$ VAMC and Yale Medical Schoo West Haven, CT 06516, USA West Haven, CT O65I6, USA Division of Gastroenterology KURT $7 A E G E R$ Division of Angiology,
University Hospital, CH-4031 Basel, Switzerland

Correspondence to: Dr Beglinger.

1 Sieber C, Beglinger C, Jaeger K, et al. Regulation of postprandial mesenteric blood flow in humans: evidence for a cholinergic nervous reflex. Gut 1991; 32: 361-6.

2 Sabba C, Ferraioli G, Genecin P, et al. Evaluation of postprandial hyperemia in superior mesenteric artery and portal vein in healthy and cirrhotic humans: an operator-blind and Doppler study. Hepatology 1991; 13: 714-8.

3 Jaeger K, Bollinger A, Valli C, et al. Measuremen of mesenteric blood flow by duplex scanning. of mesenteric blood flow

4 Moneta GL, Taylor DC, Helton WS, et al. Duplex ultrasound measurement of postprandial intestinal blood flow: effect of meal composition. Gastroenterology 1988; 95: 1294-301.

5 Norryd C, Dencker H, Lunderquist A, et al. Superior mesenteric blood flow during digestion in man. Acta Chir Scand 1975; 141: 197-202.

6 Kooner JS, Peart WS, Mathias CJ. The peptide release inhibitor octreotide (SMS 201-995) prevents the haemodynamic changes following food ingestion in normal human subjects. $Q \mathcal{F}$ Exp Physiol 1989; 74: 569-72.

7 Qamar MI, Read AE, Skidmore R, et al. Transcutaneous Doppler ultrasound measurement of superior mesenteric artery blood flow in man. Superior mesenteric

8 Beglinger C, Fried $M$, Whitehouse I, et al. Pancreatic enzyme response to a liquid meal and to hormonal stimulation. Correlation with plasma secretin and cholecystokinin levels. f Clin Invest 1985; 75: 1471-6.

9 Hildebrand P, Ensinck JW, Ketterer S, et al. Effect of a cholecystokinin antagonist on mealstimulated insulin and pancreatic polypeptide release in humans. $\mathcal{f}$ Clin Endocrinol Metabol 1991; 72: 1123-9.

10 Beglinger C, Hildebrand P, Meier R, et al. physiologic role for cholecystokinin (CCK) as a regulator of gastrin secretion in man. Gastroenterology 1991; 100: A630.

\section{Helicobacter pylori infection in healthy people}

SIR, - We have recently published the results of an epidemiological study in Gut reporting discrepancies between active Helicobacter pylori (Hp) infection determined by means of th ${ }^{13} \mathrm{C}$-urea breath test and the prevalence of anti$\mathrm{Hp}$ antibodies in healthy volunteers. Further developments in serological tests make it necessary to report additional information and to reconsider our conclusions based on the serological data presented in the paper.

A systemic humoral immune response to $H$ pylori has been searched for in many studies (including our own) by similar serologica tests, ${ }^{1-5}$ some of which have become commer cially available. They have all in common that whole bacterial cells were primarily used as antigen (acid glycine extracts or sonicated whole cell preparations or formalin treated bacteria). The antigen used in these tests, however, contains flagella proteins that are wel known to share antigenicity with flagellae of other bacteria, especially Campylobacter jejuni. ${ }^{67}$ False positive serological test results can therefore not be excluded. Thus new serological tests using purified high molecular outer membrane proteins of $\mathrm{H}$ pylori and urease as antigens have recently been developed. ${ }^{8}$ These second generation serological tests may be more specific for $H$ pylori infection.

We have investigated the sensitivity and specificity of several different serological tests in a population of patients in whom the presence or absence of $H$ pylori infection was unequivocally established. These patients all had upper gastrointestinal tract endoscopy with antral mucosal biopsies that were used for microbiological $H$ pylori culture, and a quick urease test (CLO test) and they all underwent a ${ }^{13} \mathrm{C}$-urea breath test. Sera were used only from patients in whom either all three tests were positive ( $H$ pylori infection present) or all three tests were negative (infection absent). These latter patients were also questioned abou treatment with antibiotics within the past six months and included in the present analysis only if the response was negative. Sera from this population were tested for anti-Hp antibodies with our own enzyme linked immunosorbent assay ELISA and two commercially available, first generation serological tests (anti-Hp IgG EIA Roche, Hoffman-La Roche, Basel, Switzerland, and GAP test IgG, Bio Rad Laboratories, Glattbrugg, Switzerland) and a new second generation serological test that uses a well characterised, highly immunogenic, purified $\mathrm{Hp}$-specific multicomponen antigen preparation free of cross reacting flagella proteins (anti-Hp IgG EIA Roche second generation, Hoffman-La Roche). Sera from 223 patients were tested; 64 patients had $H$ pylori infection and 159 did not. The sensitivity and specificity of the four serologica tests are shown in the Table.

\begin{tabular}{lclll}
\hline & $\begin{array}{l}\text { Meyer } \\
\text { et al }\end{array}$ & $\begin{array}{l}\text { Roche } \\
\text { lst }\end{array}$ & GAP & $\begin{array}{l}\text { Roche } \\
\text { 2nd }\end{array}$ \\
\hline Sensitivity & 100 & 93 & 94 & 97 \\
Specificity & 80 & 85 & $85(96)^{\star}$ & 93
\end{tabular}

*If test results were included that reacted slightly or strongly (specificity within parentheses) positive.

Firstly, it is obvious that the three first generation tests react positively in $15-20 \%$ of people who have no active $H$ pylori infection. If the same people are, however, tested with the second generation test, only $7 \%$ have anti-Hp without active infection. The cumulative percentage of patients reacting with either one of the three first generation tests amounted to $29 \%$, resulting in a specificity of only $71 \%$. These findings support the hypothesis that with first generation serological tests in an important fraction of people, anti-Hp antibodies may be due to non-specific binding to the antigen in the test kit rather than to specific response to $H$ pylori infection in the past. While it is still possible that healthy people eventually eliminate $H$ pylori spontaneously, this conclusion may not be drawn from our results based on the first generation serological test that was used. Similar caution however, should be used in the interpretation of virtually all studies that reported $H$ pylor prevalence data based on first generation serological tests. ${ }^{1-5}$ Epidemiological studies designed to gather information on the prevalence of $H$ pylori should preferentially use direct proof of infection rather than serology.

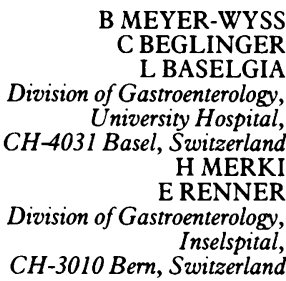

1 Meyer B, Werth B, Beglinger C, Dill S, Drewe J, Vischer WA, et al. Helicobacter pylori infection in healthy people: a dynamic process? Gut 1991; 32. 347-50.

2 Perez-Perez GI, Dworkin BM, Chodos JE, Blase MJ. Campylobacter pylori antibodies in humans. Ann Intern Med 1988; 109: 11-7.

3 Rathbone BJ, Wyatt JI, Worsley BW, et al. Systemic and local antibody responses to gastric Campylobacter pyloridis in non-ulcer dyspepsia. Gut 1986; 27: 642-7.

4 Loffeld RJLF, Stobberingh E, Flendrig JA, van Spreeuwel JP, Arends JW. Diagnostic value of an immunoassay to detect anti Campylobacter pylori antibodies in non-ulcer dyspepsia. Lancet 1989; i: 1182-5.

5 Drumm B, Perez-Perez GI, Blaser MJ, Sherman PM. Intrafamilial clustering of Helicobacte pylori infection. $N$ Engl f Med 1990; 322: 359-

6 Newell DG. Identification of the outer membrane proteins of Campylobacter pyloridis and antigenic cross-reactivity between C. pyloridis and C. jejuni. 7 Gen Microbiol 1987; 133: 163-70.

7 Hirschl AM, Pletschette M, Hirschl MH, Berger J, Stanek G, Rotter ML. Comparison of differen antigen preparations in an evaluation of the immune response to Campylobaluan of the Clin Microbiol Infect Dis 1988; 7: 570-5.

8 Dent JC, McNulty CAM, Uff JS, Gear MWL, Wilkinson SP. Campylobacter pylori urease: new serological test. Lancet 1988 ; i: 1002.

9 Evans DJ, Evans DG, Graham DY, Klein PD. A sensitive and specific serologic test for detection of Campylobacter pylori infection. Gastro enterology 1989; 96: 1004-8.

Medical treatment of bleeding peptic ulcer: old drugs, new regimens

SIR, - Haemorrhage from peptic ulcer is due to the erosion of artery at the ulcer base by the combined digestive actions of acid and pepsin. Platelet plug and clot formation (both factors being $\mathrm{pH}$ sensitive) seal the bleeding artery Dissolution of the clot is the most importan factor for peptic ulcer rebleeding. 'Intragastric acidity prolongs the duration of bleeding ${ }^{2}$ as the gastric juice contains fibrinolytic substances and a $\mathrm{pH}<7$ results in inhibition of platelet aggregation and dissolution of the clot. ${ }^{4}$ Understandably then, attempts to counteract the $\operatorname{acid}^{56}$ or pepsin ${ }^{7}$ or to inhibit fibrinolysis should result in stabilisation of the clot and prevention of rebleeding. Yet to date the efficacy of none of the above mentioned drugs 
has been shown unequivocally in the treatment of bleeding peptic ulcer.'

One of the important reasons given for lack of efficacy of conventional medical regimens in the control of bleeding from peptic ulcer is their inability to adequately control intragastric acidity by failing to maintain sustained intragastric achlorhydria, ${ }^{9}$ which has been shown experimentally to be essential for stabilisation of clot. ${ }^{4}$ Peterson and Richardson ${ }^{10}$ have shown that sustained achlorhydria can be achieved only with hourly intravenous bolus injections of cimetidine $(100 \mathrm{mg})$ with continuous nasogastric infusion of an antacid at the rate of $0.5 \mathrm{ml} / \mathrm{min}$ and not with conventional doses of $\mathrm{H}_{2}$ receptor antagonists with or without antacids. In a preliminary prospective randomised study in patients with bleeding peptic ulcer using the above regimen we have recently shown that not only could achlorhydria be maintained but also a higher rate of control of bleeding than that obtained with the standard regimen could be achieved." Furthermore, using such a regimen for all subsequent patients with bleeding peptic ulcer we achieved an overall control of bleeding in $75.4 \%$ of patients compared with $56.7 \%$ in the historical controls. ${ }^{12}$

We believe that there is increasing evidence that a relation exists between intragastric acidity, clot formation and peptic ulcer bleeding. ${ }^{11-13}$ Surprisingly, however, there has been no large study of patients with bleeding peptic ulcer treated with an intensive medical regimen ${ }_{1}^{1}$ aimed at complete neutralisation of acid and pepsin with the intent of preventing clot dissolution and rebleeding. Since such a regimen is inexpensive, easily available, and safe, we think there is an impending need for evaluating its efficacy in a large number of patients presenting with bleeding peptic ulcer.

ANIL ARORA R K TANDON All India Institute of Medical Sciences, New Delhi-110029, India

Correspondence to: $\operatorname{Dr} \mathrm{R} K$ Tandon.

1 Peterson WL. Pharmacotherapy of bleeding peptic ulcer. Is it time to give up the search? [Editorial]. Gastroenterology 1989; 97: 796-7.

2 Mann SG, Didcote S, Taylor PH, Hawkey CJ. Prolongation of intragastric bleeding by acid. Prolongation of intragas

3 Patchett SE, Enright H, Afdhal N, O'Connell W, O'Donoghue DP. Clot lysis by gastric juice: an O'Donoghue DP. Clot lysis by gastric
in vitro study. Gut 1989; 30: 1704-7.

4 Green F Jr, Kaplan M, Curtis L, Levine P. Effect of acid and pepsin on blood coagulation and platelet aggregation. A possible contributor to prolonged gastroduodenal hemorrhage. Gastroenterology 1978; 74: 38-43.

5 Collins $R$, Langman $M$. Treatment with histamine $\mathrm{H}_{2}$ receptor antagonists in acute upper gastrointestinal hemorrhage: implications of randomized trials. NEnglf Med 1985; 313: 660-6.

6 Christiansen J, Ottenjann R, Von Ars F and the study group. Placebo controlled trial with
stiansen J, Ottenjann $R$, Von Ars $F$ and the study group. Placebo controlled trial with
somatostatin analogue SMS 201-995 in the somatostatin analogue SMS 201-995 in the
bleeding peptic ulcer. Gastroenterology 1989; 97: bleeding

7 Berstad A. Experience with antipepsin agents. Scand $\mathcal{F}$ Gastroenterol 1979; 14 (suppl 55): 121-3.

8 Stael Von Holstein CCS, Eriksson SBS, Kallen R. Tranexamic acid as an aid to reducing blood transfusion requirement in gastric and duodenal bleeding. BMf 1987; 297: 7-10.

9 Reynolds JR, Walt RP, Clark AG, Hardcastle JB, Langman MJS. Intragastric $\mathrm{pH}$ monitoring in acute upper gastrointestinal bleeding and the acute upper gastrointestinal bleeding and the Aliment Pharmacol Therap 1987; 1: 23-30.

10 Peterson WL, Richardson CT. Sustained fasting achlorhydria: a comparison of medical regiachlorhydria: a comparison of medical
mens. Gastroenterology 1985; 88: 666-9.

11 Arora A, Tandon RK, Acharya SK, Tandon BN. The role of sustained achlorhydria in bleeding peptic ulcer. F Clin Gastroenterol 1991; 13: 147-
12 Arora A, Tandon RK, Acharya SK, Tandon BM Treating bleeding peptic ulcer with sustained achlorhydria. Gastroenterol fap 1991; 26: 62-5.

13 Daneshmend TK, Hawkey CJ, Langman MJS Logan RFA, Long RG, Walt RP. Omeprazole vs placebo for acute upper gastrointestinal trial in 1154 patients. Gut 1990; 31: A1206.

\section{But was the procedure really necessary?}

SIR,-Lee and Berhenne report 46 patients rendered stone and fragment free with cholecystolithoptripsy (Gut 1991; 32: 536-8). Seven patients developed recurrent calculi yet six remained asymptomatic. Of the 39 gall stone free patients, 26 were asymptomatic and six complained of persistent abdominal pain similar to that before treatment. Seven other patients rendered pain free still complained of various abdominal symptoms including bloating, cramps, indigestion, nausea, and dyspepsia.

After reading this article, I am suspicious that the symptoms suffered by many of these patients had nothing to do with the gall stones. The fact that some had apparently improved after cholecystolithotripsy does not establish that the procedure should have been done in the first place. Improvement could have been due to the powerful placebo response of the cholecystolithotripsy.

Before evaluating this study we need to know the indications for cholecystolithotripsy. Some of the patients had persistent abdominal pain similar to that before treatment. This raises the important question: Were the symptoms which permitted entry into this trial due to the gal stones? Persistent right upper quadrant abdominal pain commonly occurs in the absence of gall stones and may be due to a functional disorder of the upper gastrointestinal tract. ' Furthermore, several studies have clearly shown that the prevalence of dyspepsia is similar in those who have and do not have gall stones. ${ }^{2-4}$

It seems unlikely that cholecystitis (is there such a thing as chronic cholecystititis?) was an indication for lithotripsy since such patients are quite ill and usually require surgery fairly urgently. Their gall bladders would be unlikely to contract. We are not told that any of the patients were jaundiced or had pancreatitis, so the only remaining indication for removal of the gall stones would be biliary colic. It is possible, of course, that all the patients reported on had typical biliary colic, but this is not stated in the article.

Health ministries, third party payers, and increasingly the public are questioning the introduction of expensive new technology without proper validation. In this study cholecystolithotripsy seems to have taken place on some patients without indications for gall stone removal. Claims for the improvement of symptoms other than biliary colic are not substantiated by a double blind trial and go agains experience. $^{2+}$ If, indeed, there were valid indications for lithotripsy in the patients reported, then the authors should have made these indications explicit in the article. If not, one wonders if the patients would have been better off with no treatment at all.

W G THOMPSON Division of Gastroenterology, Ottawa Civic Hospital, University of Ottawe Ottawa, Ontario, Canada KIY $4 E$

1 Kingham JGC, Dawson AM. Origin of chronic right upper quadrant abdominal pain. Gut 1985; 26: 783-8.

2 Price WH. Gall bladder dyspepsia. BMf 1963; ii: $138-41$.
3 Bainton D, Davies DT, Evans KT, et al. Gallbladder disease; prevalence in a South Wales industrial town. Lancet 1981; i: 1147-9.

4 Barbara L, et al. A population study on the prevalence of gallstone disease. Hepatology 1987; 7: 913-7.

\section{Reply}

SIR, - Dr Thompson wants to know the indications for cholecystolithotripsy and questions if the symptoms in our patients were indeed due to gall stones. Our multidisciplinary team agrees with Dr Thompson that right upper quadrant pain occurs in the absence of gall stones. This is further substantiated by the fact that up to $50 \%$ of patients have persistence of symptoms after cholecystectomy. We gave nine references in our discussion concerning this point. Our results of lithotripsy therefore compare favourably with cholecystectomy.

We are not aware of any institution using gall stone lithotripsy where the protocol does not require the presence of gall stone colic for entry to the study. We would like to assure $\mathrm{Dr}$ Thompson that in our institution in the lithotripsy clinic gastroenterologists and surgeons refer patients for treatment only if gall stone pain is present and if these patients would otherwise have been considered for cholecystectomy. All 220 patients entered into our study were diagnosed as having gall stone pain. We therefore disagree with Dr Thompson that cholecystolithotripsy has taken place in our institution without indication. Our team has decided that patients with so called 'gall bladder dyspepsia' should not be accepted for lithotripsy. One of our previous publications (reference 13 in our article) is more explicit in the acceptance protocol, stating that 'evidence of pain due to the presence of gallstones' is required.

S H LEE H J BURHENNE Department of Radiology, Vancouver General Hospital, 855 West 12 th Ave Vancouver BC, Canada V5Z IM9

\section{BOOK REVIEWS}

Gastrointestinal symptoms: clinical interpretation. Edited by J Edward Berk and Walter Haubrich. (Pp 271; illustrated; $£ 28.00$.) Wolfe Medical Publishing, London, 1991.

The modern medical curriculum lays increasing emphasis on 'communication skills.' When I first encountered this jargon, I thought it had something to do with computers, but was reassured to find that it simply means the ability to talk to people. Either as a consequence of this educational initiative, or of the 'holistic' philosophy behind it, medical students seem to be better at history taking. This should be good news for gastroenterology in which, more than in any other branch of internal medicine (if only because the physical signs of disease are so often vague or absent), the aphorism, 'listen to the patient - he will tell you the diagnosis' holds true. But it isn't, because the modern science of gastroenterotechnology attracts the gadget minded and the would be surgeon and repels 